\title{
Sualtı kablosuz optik haberleşme kanalının Monte Carlo tabanlı ışınım transfer denklemi ile modellenmesi
}

\author{
Modeling of underwater wireless optical communication channel by Monte Carlo based \\ radiative transfer equation
}

\author{
Cenk ALBAYRAK ${ }^{* 1, a}$, Yiğit MAHMUTOĞLU ${ }^{2, b}$, Kadir TÜRK ${ }^{3, c}$ \\ ${ }^{1}$ Karadeniz Teknik Üniversitesi, Of Teknoloji Fakültesi, Enerji Sistemleri Mühendisliği Bölümü, 61830, Trabzon \\ ${ }^{2}$ Recep Tayyip Erdoğan Üniversitesi, Mühendislik Fakültesi, Elektrik ve Elektronik Mühendisliği Bölümü, 53100, Rize \\ ${ }^{3}$ Karadeniz Teknik Üniversitesi, Mühendislik Fakültesi, Elektrik-Elektronik Mühendisliği Bölümü,61080, Trabzon
}

• Geliş tarihi / Received: 23.03.2020 • Düzeltilerek geliş tarihi / Received in revised form: 27.10.2020 • Kabul tarihi / Accepted: 12.11 .2020

\begin{abstract}
$\ddot{O} z$
Önemli askeri ve endüstriyel uygulama alanlarından dolayı, sualtı ortamında gerçek zamanlı ve yüksek hızlı bilgi iletişimi sağlayabilen sualtı kablosuz optik haberleşme (Underwater Wireless Optical Communication, UWOC) sistemlerine olan ilgi giderek artmaktadır. Güvenilir UWOC sistemlerinin tasarlanabilmesi için sualtı kablosuz optik haberleşme kanal karakteristiğinin gerçekçi ve doğru bir şekilde ortaya konulması önem arz etmektedir. Sualtı ortamının benzersiz optik özelliklerinden dolayı fazlasıyla karmaşık bir yapıya sahip olan UWOC kanalı, ışınım transfer denklemi (Radiative Transfer Equation, RTE) ile tamamen modellenebilmektedir. Fakat, RTE’nin kesin bir analitik çözümünü bulmak zordur. Bu çalışmada, RTE'nin yüksek doğrulukta çözümü ve UWOC kanal karakteristiğinin elde edilebilmesi için kullanılan Monte Carlo yaklaşımı ve işlem adımları detaylı olarak verilmiştir. Literatürde yaygın olarak kullanılan farklı su türleri için UWOC kanalının birim vuruş tepkileri elde edilmiş olup, kanal karakteristiklerinin yüksek doğruluğu ve hassasiyeti için yaklaşık modeller yerine literatürde kabul gören deneysel ölçümler dikkate alınmıştır. Elde edilen sonuçlara göre, UWOC sisteminin bilgi iletişim mesafeleri ele alınan su türleri için karşılaştırılmıştır.
\end{abstract}

Anahtar kelimeler: Birim vuruş tepkisi, Monte Carlo yaklaşımı, Sualtı kablosuz optik haberleşme

\begin{abstract}
Due to the important military and industrial application areas, the interest in underwater wireless optical communication (UWOC) systems, which can support real-time and high-speed data communication in the underwater environment, gradually increases. In order to design reliable UWOC systems, it is important to reveal realistic and accurate underwater wireless optical communication channel characteristics. UWOC channel, which has a very complex structure due to the unique optical characteristics of the underwater environment, can be fully modeled by the radiative transfer equation (RTE). However, it is difficult to find an exact analytical solution of RTE. In this study, Monte Carlo approach and its operation steps are given in detail for the high accuracy solution of RTE and obtaining UWOC channel characteristic. For the different water types commonly used in the literature, the impulse responses of UWOC channel have been obtained and instead of approximate models experimental measurements recognized in the literature have been considered for the high accuracy and precision of the channel characteristics. According to the obtained results, data communication distances of the UWOC system are compared for the considered water types.
\end{abstract}

Keywords: Impulse response, Monte Carlo approach, Underwater wireless optical communications

\footnotetext{
*a Cenk ALBAYRAK, albayrak.cenk@ktu.edu.tr, Tel: (0462) 37784 66, orcid.org/0000-0002-1989-1697

${ }^{\mathrm{b}}$ orcid.org/0000-0003-4409-2587 $\quad{ }^{\mathrm{c}}$ orcid.org/0000-0002-4504-8417
} 


\section{Giriş}

Sualtı ortamında gerçek zamanlı ve yüksek hızlı kablosuz bilgi aktarımı konusuna olan talep, çeşitli askeri ve endüstri uygulama alanlarından (sualtı keşfi, liman güvenliği ve gözetimi, çevre denetimi ve kirlilik kontrolü, bilimsel veri toplama, petrol sahası keşfi vb.) dolayı hızla artmaktadır (Miramirkhani ve Uysal, 2017; Chen vd., 2020; Yuan vd., 2020). Hali hazırda çeşitli sualtı uygulamaları için kablolu, yani fiber optik olarak bilgi aktarımı yapılabilmektedir. Fakat yüksek kurulum maliyetleri, işletme zorlukları ve yeniden düzenleme esnekliklerinin zayıf olması bu sistemlerin kullanımını kisitlayıc1 bir hale getirmektedir. Bu anlamda sualtı uygulamaları için kablosuz bilgi aktarımı, gelecek vadeden bir çözüm olarak öne çıkmaktadır (Kaushal ve Kaddoum, 2016; Miramirkhani ve Uysal, 2017; Yuan vd., 2020).

Sualtı ortamında kablosuz bilgi aktarımı radyo frekans1 (Radio Frequency, RF), akustik ve optik dalgalar kullanılarak yapilabilmektedir (Zeng vd., 2017; Miramirkhani ve Uysal, 2017; Shihada vd., 2020). RF dalgaları kullanılarak sualtı ortamında Mbps seviyelerinde haberleşme hızı sağlanabiliyor olmasına rağmen, RF dalgaları sualtı ortamında oldukça fazla zayıflamaktadır. Bu nedenle, RF sistemleriyle sualtı ortamında bilgi iletişimi ancak 10 metreye kadar, yani çok kısa mesafelerle sinırlanmaktadır. Akustik dalgalar, sualtında bilgi iletişimin kilometreler mertebelerinde yapılabilmesine olanak sağlasa da, akustik sistemlerin haberleşme hızları kbps seviyeleri ile sınırlanmakta olup, gecikme süreleri de yüksektir. $\mathrm{Bu}$ nedenle akustik sistemler, görüntü ve gerçek zamanlı video iletimi gibi yüksek bant genişliği gerektiren sualtı uygulamalarında tercih edilememektedir. Diğer taraftan optik dalgalar yüksek bant genişliğine sahip olmalarına rağmen, sualtı ortamının bozucu etmenlerinden fazlasiyla etkilenmektedirler. Fakat, görünür 1şık spektrumunun mavi / yeşil bantlarını kullanan sualtı kablosuz optik haberleşme (Underwater Wireless Optical Communication, UWOC) sistemlerinde bu etkilerin gücü spektrumun diğer bölgelerine göre en aza inmektedir (Tang vd., 2014; Chen vd., 2020). Bu durum UWOC sistemlerini ilgi çekici hale getirmiş olup, bu sistemler ile 10 - 100 metre arası mesafelerde Gbps haberleşme hızı seviyelerinde bilgi iletişimi sağlanabilmektedir (Zeng vd., 2017; Chen vd., 2020). Bu nedenle UWOC sistemleri, gerçek zamanlı video iletişimi, uzaktan algılama ve seyrüsefer, görüntüleme ve yüksek veri hacimli sensör ağı gibi sualtı uygulamaları için önemli bir çözümdür (Tang vd., 2014).

Güvenilir UWOC sistemlerinin tasarlanabilmesi ve UWOC sistemleri için önerilen yeni yöntemlerin geçerlilik kazanabilmesi açılarından UWOC kanal yapısının gerçekçi ve doğru bir şekilde ortaya konulması önem arz etmektedir (Zeng vd., 2017). Sualtı ortamının benzersiz optik özelliklerinden dolay1, ışığın sudaki yayılımı oldukça karmaşık bir yapıya sahiptir (Chen vd., 2020). Tanımlaması güç olan sualtı kablosuz optik haberleşme kanalı, ışınım transfer denklemi (Radiative Transfer Equation, RTE) ile tamamen modellenebilmektedir (Miramirkhani ve Uysal, 2017). Birçok bağımsız değişkenin integral-diferansiyel denklemini içeren RTE temel olarak, bir ortamdan geçen 1 şı dalgasını enerjinin korunumu kanuna göre tamamen tanımlayabilmektedir. Fakat, elde edilmesi karmaşık ve uzun olan bu denklemin kesin bir analitik çözümünü elde etmek zordur. Bu nedenle son yıllarda literatürde RTE'nin çözümü için bazı basitleştirici varsayımlara dayanan yaklaşık analitik çözümler ve sayısal yöntemler önerilmiştir (Kaushal ve Kaddoum, 2016; Zeng vd., 2017; Miramirkhani ve Uysal, 2017). Önerilen analitik çözümler ile yüksek doğruluğa ulaşılamamaktadır ve sayısal yöntemler de ancak bazı şartlar doğrultusunda uygulanabilmektedirler. Bunlara alternatif olarak daha esnek, programlanması kolay ve doğruluğu yüksek olan Monte Carlo yaklaşımı, sualtı kablosuz optik haberleşme kanalının modellenebilmesi ve RTE'nin çözümü için literatürde yaygın olarak kullanılmaktadır (Tang vd., 2014; Zeng vd., 2017;). Monte Carlo yaklaşımında, istatistiksel verilere dayanarak 1şık kaynağından çıkan ve alıcıya doğru yol alan çok sayıda foton üretilmektedir ve her fotonun sualtı ortamı ile etkileşimi hesaplanmaktadır (Yuan vd., 2020).

Bu çalışmada, UWOC kanalını modellemek için Monte Carlo tabanlı RTE yöntemi kullanılmış olup, Monte Carlo yaklaşımının işlem adımları ve gerçeklenmesi detaylı olarak irdelenmiştir. Literatürde yaygın olarak kullanılan berrak, kıyı ve liman (clear, coastal ve harbor) deniz suyu gibi üç farklı ortam için UWOC kanalının dürtü yanıtları, verici-alıcı arasındaki farklı mesafe değerleri için Monte Carlo yaklaşımıyla elde edilmiş ve sunulmuştur. Çalışmada nümerik hesaplamaların hassasiyetinin yüksek olması için yaklaşık modeller yerine Petzold (1972) çalı̧̧masında verilmiş olan ve literatürde kabul gören deneysel ölçümler dikkate alınmıştır. Alıcı ve verici arasında herhangi bir nesneden yansima olmamasina rağmen sualtı ortamının yüksek saçılma etkisinden 
dolayı kanalın dürtü yanıtları zamanda yayılmaktadır. Çalışmada kanal dürtü yanıtlarının yanında kanalın ortalama karekök gecikme yayılımı $\left(\tau_{R M S}\right)$ ve alınan gücün haberleşme mesafesine göre değişimi de sunulmuştur. Elde edilen sonuçlar kullanılarak ihtiyaç duyulan ortam, verici-alıcı arası mesafe ve haberleşme hızındaki UWOC senaryosu için sistem sınırları belirlenebilir ve verici-alıc1 yapıları tasarlanabilir. Amaçlanan senaryoya göre direk görüş durumunda bile çok yollu kanal etkilerinin ortaya çıkacağ 1 anlaşılmaktadır.

\section{Sualtı kablosuz optik haberleşme kanalı}

Sualtı ortamında 1şı yayılımını olumsuz yönde etkileyen, emilim (absorption) ve saçılma (scattering) olarak bilinen, iki ana süreçten söz edilmektedir (Gabriel vd., 2013; Dong vd., 2017; Shihada vd., 2020). Emilim, fotonların su molekülü ve su içindeki diğer parçacıklar ile etkileşmesi sonucu termal enerjiye dönüşüp kaybolduğu geri dönüşü olmayan bir süreçtir. Saçılma ise, fotonların sualtı ortamının molekülleri ve atomları ile etkileşmesi sonucu iletim yönlerinin değişmesi sürecidir. $\mathrm{Bu}$ da, alıcida daha az foton yakalanmasına neden olduğundan enerji kaybı söz konusu olmaktadır.

Bir UWOC sisteminde emilim ve saçılma süreçleri istenmeyen üç etkiye neden olmaktadır (Zeng vd., 2017). Birincisi, emilim nedeniyle yayılma süresi boyunca 1şı̆̆ı̀ enerjisinin sürekli olarak azalmasıdır. Bu durum, UWOC sisteminin iletişim mesafesini sınırlamaktadır. İkincisi, alıcı lens çapının boyutu sonlu olduğu için saçılma sonucu 1şık hüzmesinin yayılması ve alıcı tarafından toplanan foton sayisinda bir azalma meydana gelmesidir. Bu durum, alıcı taraftaki işaret gürültü oranını (Signal-to-Noise Ratio, SNR) düşürmektedir. Üçüncüsü ise, saçılmadan dolayı vericiden gönderilen her bir fotonun alıcıya farklı zaman aralıklarında ulaşması sonucu çok yolluluğun oluşması, başka bir ifadeyle semboller aras1 girişimin (Intersymbol Interference, ISI) meydana gelmesidir.

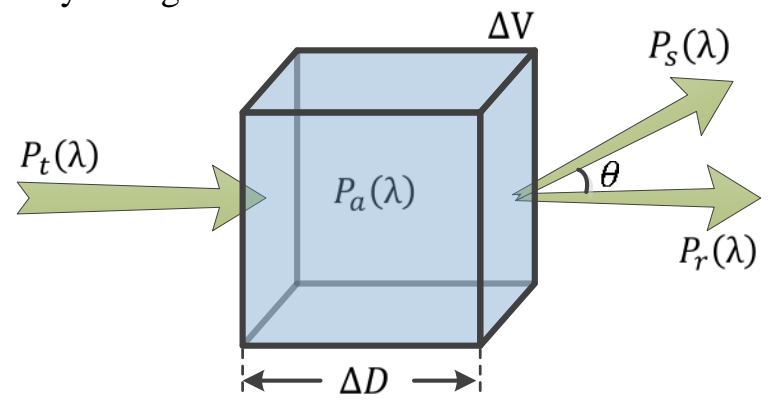

Şekil 1. $\Delta V$ hacmindeki bir su ortamından geçen 1şın demetinin davranışı
Emilim ve saçılma süreçleri Şekil 1'de gösterilmiş olup, burada $\lambda$ dalga boyuna sahip bir 1şın demetinin $\Delta \mathrm{V}$ hacminde ve $\Delta \mathrm{D}$ genişliğindeki bir su ortamına ulaştığ varsayılmaktadır. Söz konusu su ortamına $P_{t}(\lambda)$ gücünde bir 1şık demeti geldiğinde, bu 1şın demetinin $P_{a}(\lambda)$ gücündeki bir kısmı su ortamında emilirken, $P_{S}(\lambda)$ gücündeki bir kısmı ilgili su ortamından çıkarken saçılarak başka bir $\Delta \mathrm{V}$ hacmi ve $\Delta \mathrm{D}$ genişliğine sahip su ortamına girmektedir. Emilim ve saçılma süreçlerinden geçen 1şın demetinin geriye kalan $P_{r}(\lambda)$ gücündeki kısmı ise arzu edilen şekilde yoluna devam etmektedir. Enerjinin korunumu kanununa göre, Şekil 1'deki su ortamına gelen ve su ortamından çıkan 1şınlar için, (1) denkleminin sağlanması gerekmektedir (Kaushal ve Kaddoum, 2016).

$P_{t}(\lambda)=P_{a}(\lambda)+P_{s}(\lambda)+P_{r}(\lambda)$

Söz konusu su ortamı için emilim ve saçılma katsayıları sirasiyla (2) ve (3) denklemlerinde verildiği gibi, $\Delta \mathrm{D}$ genişliğinin çok küçük bir değeri için, emilim ve saçılma güçlerinin gelen güce oranıyla hesaplanmaktadır (Zend vd., 2017).

$a(\lambda)=\lim _{\Delta \mathrm{D} \rightarrow 0}\left(\frac{P_{a}(\lambda)}{\Delta \mathrm{D} P_{t}(\lambda)}\right)$

$b(\lambda)=\lim _{\Delta \mathrm{D} \rightarrow 0}\left(\frac{P_{s}(\lambda)}{\Delta \mathrm{D} P_{t}(\lambda)}\right)$

Sualtı optiğinde, emilim ve saçılma etkileri (4) denkleminde verildiği gibi $c(\lambda)$ zayıflama katsayısı ile tanımlanmaktadır. Sönümleme katsayısı olarak da bilinen $c(\lambda)$ katsayısı, emilim ve saçılmanın enerji kaybı üzerindeki toplam etkilerini tanımlamaktadır. $a(\lambda), b(\lambda)$ ve $c(\lambda)$ katsayıları, su türüne ve kaynağın dalga boyuna bağlı olarak değişmektedirler (Kaushal ve Kaddoum, 2016; Zend vd., 2017).

$c(\lambda)=\mathrm{a}(\lambda)+\mathrm{b}(\lambda)$

Emilim ile karşılaştırıldığında, saçılma etkisi dalga boyundan nispeten bağımsızdır (Zend vd., 2017). Saçılmayı etkileyen baskın faktör su içindeki partikül madde yoğunluğu olup, sicaklık, basınç, tuzluluk, akınt1, fitoplankton ve detritus yoğunlukları gibi etkenler saçılma katsayısını değiştirmektedir. Söz konusu bu etkenlerin baskın olduğu su türüne bağl1 olarak saçılmanın belirlenebilmesi için literatürde Rayleigh ve Mie saçılma modelleri önerilmiştir (Zend vd., 2017; Yuan vd., 2020). Saf deniz suyunda saçılma, Rayleigh dağılımı ile daha iyi modellenirken, okyanus suyu için ise Mie daha iyi bir saçılma 
modelidir. Saçılma etkilerini daha doğru ifade edebilmek için literatürde kullanılan diğer bir tanımlama ise hacim saçılma fonksiyonudur (Volume Scattering Function, VSF) (Petzold, 1972; Zeng vd., 2017). VSF, birim su hacmine gelen birim ışınımın saçılma yoğunluğu olarak ifade edilmektedir. Literatürde, saçılma açısının $\left(\theta^{s}\right)$ belirlenmesi için yaygın olarak Petzold'un deneysel VSF ölçümleri kullanılmaktadır (Petzold, 1972). Petzold (1972) çalışmasında, berrak, kıyı ve liman okyanus sularında deneysel olarak farklı saçılma açıları için ölçülen VSF değerleri sunulmuştur. $\mathrm{Bu}$ çalışmada elde edilen sonuçlar için, bahsi geçen saçılma modelleri yerine, Petzold'un üç farklı su türü için vermiş olduğu deneysel ölçüm değerleri dikkate alınmıştır.

Tablo 1. Petzold (1972) çalışmasında deneysel ölçümler ile elde edilen $a(\lambda), b(\lambda)$ ve $c(\lambda)$ katsayıları $(\lambda=530 \mathrm{~nm})$

\begin{tabular}{|l|c|c|c|}
\hline Su türü & $\boldsymbol{a}(\boldsymbol{\lambda})\left(\boldsymbol{m}^{\mathbf{- 1}}\right)$ & $\boldsymbol{b}(\boldsymbol{\lambda})\left(\boldsymbol{m}^{-\mathbf{1}}\right)$ & $\boldsymbol{c}(\boldsymbol{\lambda})\left(\boldsymbol{m}^{-\mathbf{1}}\right)$ \\
\hline Berrak & 0.114 & 0.037 & 0.151 \\
\hline Kiy1 & 0.179 & 0.219 & 0.398 \\
\hline Liman & 0.366 & 1.824 & 2.190 \\
\hline
\end{tabular}

Bu çalışmada, berrak, kıyı ve liman olmak üzere üç farklı su türü için Petzold (1972) çalışmasında yer alan sirasiyla "AUTEC - Test 161 - 13JUL71 Station 8", "HAOCE - 05AUG71 - Station 11" ve "NUC - 05OCT71 - Station 2040" deneysel ölçümleri kullanılmıştır. Işık kaynağı dalga boyu $530 \mathrm{~nm}$ için alınan bu ölçümlerde $a(\lambda), b(\lambda)$ ve $c(\lambda)$ katsayıları Tablo 1'de verildiği gibi rapor edilmiştir.

\section{Sualtı kablosuz optik haberleşme kanal modeli için Monte Carlo Yaklaşımı}

Sualtı kablosuz optik haberleşmede Monte Carlo yaklaşımı, RTE'nin çözümünü gerçekleştirmek için istatistiksel verileri kullanan bir sayısal yöntemdir (Tang vd., 2014; Zeng vd., 2017). RTE'nin literatürdeki analitik çözümleriyle karşılaştırıldığında Monte Carlo yaklaşımı, saçılma açılarında herhangi bir kısıtlama olmaksızın, çok sayıda saçılmanın meydana geldiği deniz suyu gibi ortamlarda optik haberleşme kanalını modellemek için yaygın olarak kullanılmaktadır (Tang vd., 2014). Monte Carlo yaklaşımında, 1 şı kaynağından belirli dağılımlara göre tanımlanmış azimut ve zenit açılarıyla yayılan her fotonun takibi, sualtı ortamında belli dağılımlara göre etkileşime girdiği emilim ve saçılma süreçleri hesaplanarak yapılabilmektedir (Ding vd., 2009). Bunun sonucunda da, sualtı kablosuz optik haberleşme kanalının karakteristiği birim vuruş tepkisiyle değerlendirilebilmektedir.

UWOC sistemleri için uygulanan Monte Carlo yaklaşımı bazı temel kurallara dayanmaktadır (Dong vd., 2017). Bunlar; foton konumları Kartezyen koordinat düzleminde $(\mathrm{x}, \mathrm{y}, \mathrm{z})$ tanımlanır. Foton hareket yönü belirli dağılımlara göre üretilen zenit ve azimut açılarına göre belirlenir, başlangıçta her foton yayılma zamanı ve foton ağırlığı sirasıyla sıfır ve bir olarak belirlenir, her fotonun başlangıç hareket yönü 1şık kaynağının ayrılma açısı (divergence angle) ve açısal yoğunluk dağılımına (angular intensity distribution) bağlı olarak hesaplanır şeklinde özetlenebilir (Ding vd., 2009). Işık kaynağından yayıldıktan sonra her fotona, yol aldığı her mesafe için, önce emilim süreci uygulanır ve belirlenen bir foton ağırlığı eşik değerinin altında kalan fotonların tamamen emildiği kabul edilir. Emilim süreci sonrasında ağırlığı eşik değerin üstünde kalan fotonlara saçılma süreci uygulanır ve yeni azimut, zenit açıları belirlenerek fotonun yeni hareket yönü bu açılara bağlı olarak hesaplanır. $\mathrm{Bu}$ işlem devam ederken herhangi bir foton, alıcı lens düzlemine ulaşmışsa ve geliş açısı alıcının görüş alanının (Field of View, FOV) içinde ise alıcı tarafta o anki ağırlığ 1 ile alındığı kabul edilir. Alınan her fotonun alıcıya ulaşma zamanı, fotonun kat ettiği toplam yol ve hızına bağlı olarak hesaplanır, kayıt edilir. Böylece, ışık kaynağından yayılan fotonların ne kadarının, zamanın hangi anında alıcıya ulaştığı hesaplanabilir ve bunun sonucunda da kanalın dürtü yanıtı elde edilebilir (Ding vd., 2009; Tang vd., 2014).

Sualtı kablosuz optik haberleşme kanalının birim vuruş tepkisinin daha yüksek doğrulukta ve hassasiyette elde edilebilmesi için Monte Carlo yaklaşımında takibi yapılan foton sayısının arttırılması gerekmektedir (Yuan vd., 2020). (Tang vd., 2014) çalışmasında, $10^{9}$ foton sayısı, $10^{-6}$ foton ağırlı̆̆ eşik değeri için yüksek hassasiyet sağlanabildiği gösterildiğinden, biz de çalışmamızda aynı değerleri dikkate aldık. Monte Carlo yaklaşımının blok diyagramı Şekil 2'de verilmiştir ve çalışmanın takip eden alt bölümlerinde her bir blok detaylı olarak ele alınmıştır. Blok diyagramda verildiği gibi Monte Carlo yaklaşımının sonucunda, verici birim 1 şık 
kaynă̆ından çıkan çok sayıda fotondan, alıcı birim foto-detektör tarafından alınabilenlerinin ağılık ve varış zaman bilgileri kayıt edilmektedir (Tang vd., 2014). Kaydı tutulan bu bilgiler kullanılarak kanalın dürtü yanıtının elde edilmesi işleminde, foto-detektör tarafindan aynı zaman aralıklarında alınan fotonların ağırlık bilgileri toplanmaktadır ve üretilen bütün fotonların ağırlıklarının toplamına bölünerek normalize edilmektedir. Referans alınan (Tang vd., 2014) çalışmasında söz konusu zaman aralığ $10^{-10}$ saniye olarak belirlenmiş olup, bu çalışmada da kanalın dürtü yanıtının hesabı için aynı değer dikkate alınmıştır.

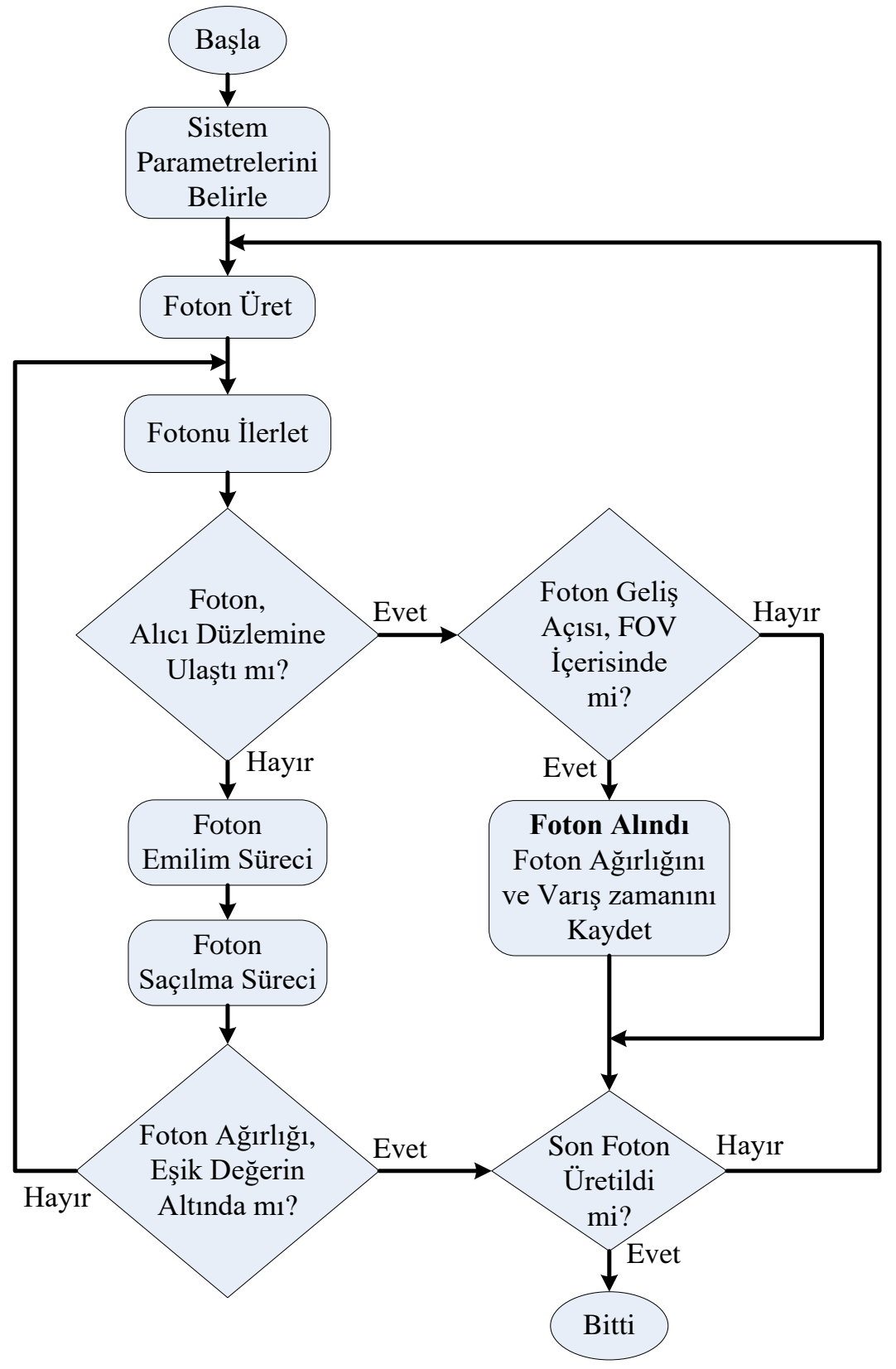

Şekil 2. Monte Carlo yaklaşımının blok diyagramı

\subsection{Sistem parametrelerinin belirlenmesi}

Monte Carlo yaklaşımının başlangıcını temsil eden bu bloğun içerisinde, ele alınacak olan UWOC sisteminin parametreleri tanımlanır. Buna göre, su türüne bağlı olarak $a(\lambda), b(\lambda)$ ve $c(\lambda)$ katsayıları, 1şık kaynağından yayılacak olan foton sayısı $N$, foton ağılık eşiği $w_{\text {eșik }}$, 1şık kaynağının konumu $\left(\mathrm{Tx}_{\mathrm{x}}, \mathrm{Tx}_{\mathrm{y}}, \mathrm{Tx}_{\mathrm{z}}\right)$, ışık kaynağının normalinin $\mathrm{x}$ ekseni ile yaptığı açı $\theta_{t}$, vericinin ışın yayma açısı $\Phi_{t}$, alicinın konumu $\left(\mathrm{Rx}_{\mathrm{x}}, \mathrm{Rx}_{\mathrm{y}}, \mathrm{Rx}_{\mathrm{z}}\right)$, alıcinın normalinin x ekseni ile yaptığı açı $\theta_{r}$, alıcı görüş alanı $\Phi_{r}$, alıcı lens çapı $D_{r}$, 1şık hızı $c$ ve ortamın kırılma indisi $n_{s u}$ büyüklüklerinin değerleri belirlenir (Ding vd., 2009; Tang vd., 2014). Bu parametrelerin çoğu Şekil 3'te verici ve alıcı birimlerin örnek bir gösterimi olarak verilen geometrik yapıda görülmektedir. 

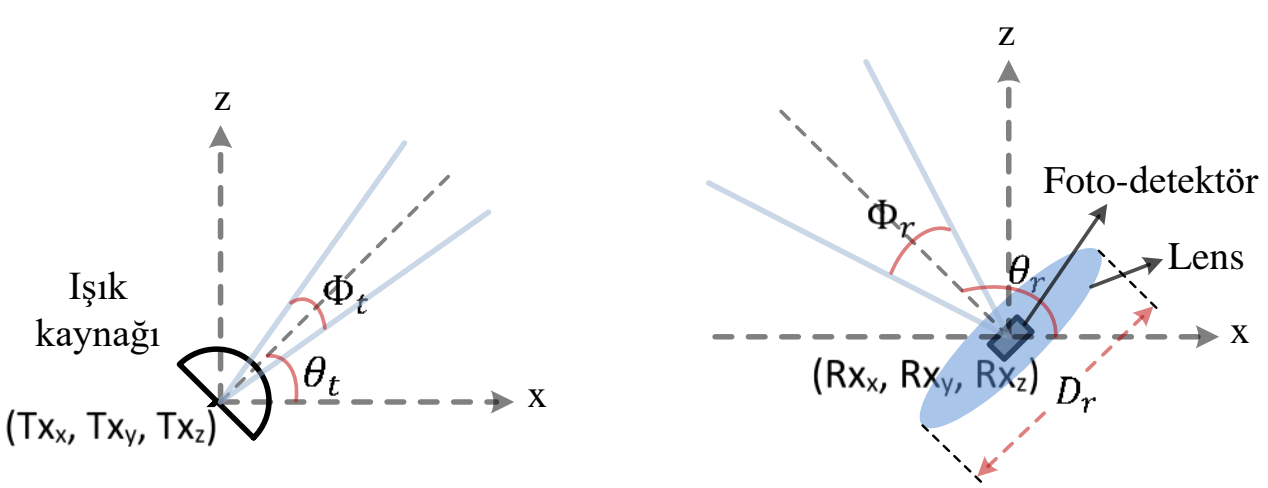

Şekil 3. Bir sualtı kablosuz optik haberleşme sistemindeki verici ışık kaynağı ve alıcı foto-detektör birimlerin geometrik gösterimi

\subsection{Foton üretimi}

Işık kaynă̆ından çıkan her fotonun sualtı ortamındaki yayılımın takibi birbirinden bağımsız olarak yapılmaktadır. $\mathrm{Bu}$ nedenle, bu blokta üretilecek olan her bir fotonun ağırlığı, konumu ve hareket yönü başlangıç parametreleri birbirinden bağımsız olarak tanımlanır. Üretilen her fotonun başlangıçtaki zaman, konum ve ağırlık parametreleri ise ortaktır ve sirasıyla sıfir saniye, verici konumu ve birim ağırlık, yani 1, şeklinde belirlenir (Prahl vd., 1989; Tang vd., 2014; Dong vd., 2017). Başlangıç hareket yönü $\left(\mu_{x}^{0}, \mu_{y}^{0}, \mu_{z}^{0}\right)$ ise belirli dağılımlara göre belirlenen azimut $\Phi^{0}$ ve zenit $\theta^{0}$ başlangıç açıları kullanılarak hesaplandığından dolayı her foton için farklı olmaktadır. Zenit açısı, foton yönünün z ekseni ile yaptığı açıyı, azimut açısı ise foton yönünün $x-y$ düzlemine olan iz düşümünün $\mathrm{x}$ ekseni ile yaptığ açıyı temsil etmektedir (Tang vd., 2014). Düzgün yayılımlı bir 1şık kaynağı için, Şekil 3'te verilen verici parametreleri de dikkate alınarak, başlangıçtaki foton azimut ve zenit açıları sırasıyla (5) ve (6) denklemlerinde verildiği gibi hesaplanmaktadır (Ding vd., 2009; Tang vd., 2014).

$\Phi^{0}=2 \pi R^{\left(\Phi^{0}\right)}$

$\theta^{0}=\cos ^{-1}\left(1-R^{\left(\theta^{0}\right)}\left(1-\cos \left(\frac{\Phi_{t}}{2}\right)\right)\right)+\frac{\pi}{2}-\theta_{t}$

Bu denklemlerde $R^{\left(\Phi^{0}\right)}$ ve $R^{\left(\theta^{0}\right)}$, sifir ile bir arasında düzgün dağılımlı iki bağımsız rasgele değişkendir. (5) ve (6) denklemleriyle belirlenen başlangıç açıları kullanılarak fotonun başlangıçtaki yönü (7) denklemiyle hesaplanır (Ding vd., 2009; Cox, 2012).

$$
\begin{aligned}
& \mu_{x}^{0}=\cos \left(\Phi^{0}\right) \sin \left(\theta^{0}\right) \\
& \mu_{y}^{0}=\sin \left(\Phi^{0}\right) \sin \left(\theta^{0}\right) \\
& \mu_{z}^{0}=\cos \left(\theta^{0}\right)
\end{aligned}
$$

$\mathrm{Bu}$ denklemler literatürde, doğrultu kosinüsü (direction cosine) olarak bilinmektedir. Düzgün yayılımlı olmayan bir 1şık kaynağı için $R^{\left(\theta^{0}\right)}$ rasgele değişkenini, 1şık kaynağının açısal yoğunluk dağılımına bağlı olarak elde etmek gerekir (Ding vd., 2009).

\subsection{Foton ilerlemesi}

Işık kaynağından çıkan her foton sualtı ortamında, ağırlığ 1 belirlenen bir eşik değerin altına düşmediği ve alıcı taraftan alınmadığı sürece, Monte Carlo yaklaşımı için verilen blok diyagramın her yinelemesinde $\Delta d$ mesafesi kadar yol almaktadır. Sualtı ortamında yayıldığı her $\Delta d$ mesafesinde foton, takip eden alt başlıklarda açıklanacağı gibi, emilim ve saçılma süreçlerine maruz kalmaktadır. İlgili foton için bu mesafe, blok diyagramın her yinelemesinde (8) denkleminde verildiği gibi hesaplanmaktadır (Prahl vd., 1989; Ding vd., 2009; Tang vd., 2014).

$\Delta d=-\ln \left(R^{(d)}\right) / c(\lambda)$

Burada $R^{(d)}$, sifir ile bir arasında değer alan düzgün dağ 1 lımlı rasgele bir değişkeni temsil etmektedir. Sualtı ortamında $\Delta d$ mesafesi kadar yol aldiktan sonra fotonun yeni konumu $\left(x_{i+1}, y_{i+1}, z_{i+1}\right)$, fotonun yol almadan önceki konumu $\left(x_{i}, y_{i}, z_{i}\right)$ ve hesaplanmış olan hareket yönü $\left(\mu_{x}^{i}, \mu_{y}^{i}, \mu_{z}^{i}\right)$ dikkate alınarak (9) denkleminde verildiği gibi hesaplanır (Prahl vd., 1989; Ding vd., 2009). 
$x_{i+1}=x_{i}+\mu_{x}^{i} \Delta d$

$y_{i+1}=y_{i}+\mu_{y}^{i} \Delta d$

$z_{i+1}=z_{i}+\mu_{z}^{i} \Delta d$

\subsection{Emilim süreci}

Sualtı ortamında, hesaplanan $\Delta d$ mesafesi kadar yol alan her fotona emilim süreci uygulanmaktadır. $\mathrm{Bu}$ sürece maruz kalan her fotonun ağırlığ $w^{i+1}$, emilim süreci uygulanmadan önceki ağırllğı $w^{i}$ ve su türüne bağlı olarak değişen emilim ve zayıflama katsayılarına bağlı olarak (10) denkleminde verildiği gibi hesaplanmaktadır (Tang vd., 2014).

$w^{i+1}=\left(1-\frac{a(\lambda)}{c(\lambda)}\right) w^{i}$

Denklemden anlaşılacağ yayılan her fotonun ağırlığı, kat ettiği her $\Delta d$ mesafesinde belli oranda azalmaktadır. A ğırlı̆̆ belirlenmiş bir eşik değerin altında kalan fotonun, kanal dürtü yanıtına önemli ölçüde etki etmeyeceği kabul edilerek, takibine son verilir (Ding vd., 2009; Tang vd., 2014). Sonrasinda ise yeni bir foton üretimine geçilerek $o$ fotonun takibinin yapılmasına devam edilir ve bu işlem son foton kalana kadar devam eder.

\subsection{Saçılma süreci}

Monte Carlo yaklaşımında, emilim süreci uygulanan ve ağırlığı eşik değerden küçük olmayan her fotona saçılma süreci uygulanmaktadır. Saçılma sürecinin sonucunda fotonun hareket yönü su türüne bağlı olarak değişmektedir. Dolayısıyla saçılma sürecinde, yeni azimut ve zenit açıları su türüne bağlı olarak belirlenir ve bu açı bilgileri kullanılarak fotonun yeni hareket yönünü hesaplanır (Ding vd., 2009; Tang vd., 2014). Saçılma azimut açısı $\Phi^{s}$, (11) denkleminde verildiği gibi, başlangıçtaki foton azimut açısıyla aynı şekilde belirlenmektedir.

$\Phi^{S}=2 \pi R^{\left(\Phi^{S}\right)}$

Burada $R^{\left(\Phi^{S}\right)}$ sıfır ile bir arasında düzgün dağılımlı rasgele bir değişkendir. Dolayısıyla, saçılma azimut açısı $[0,2 \pi]$ arasında değişmektedir. Saçılma sürecindeki en önemli parametre saçılma zenit açısının belirlenmesidir. Literatürde, HenyeyGreenstein (HG) ve iki koşullu HG (Two Terms $\mathrm{HG}$, TTHG) fonksiyonları gibi bazı kapalı form ifadeleri saçılma zenit açısını belirlemek için önerilmiştir (Gabriel vd., 2013; Tang vd., 2014). Fakat, bu yaklaş1k modeller küçük ve büyük zenit aç1larının belirlenmesinde hassas sonuç verememektedirler. Saçılma zenit açısının daha hassas belirlenebilmesi için bu çalışmada, Petzold (1972) çalışmasında deneysel olarak elde edilmiş olan ve literatürde kabul gören VSF ölçümleri kullanılmıştır. Petzold'un çalışmasında, farklı su türlerinin saçılma zenit açılarının kümülatif dağılım fonksiyonları (Cumulative Distribution Function, CDF) sunulmuş olup, bu dağılımlar kullanılarak saçılma zenit açısı $\theta^{s}$ belirlenebilmektedir.

İlgili fotonun yeni hareket yönü $\left(\mu_{x}^{i+1}, \mu_{y}^{i+1}, \mu_{z}^{i+1}\right)$, fotonun saçılma sürecinden önceki hareket yönü $\left(\mu_{x}^{i}, \mu_{y}^{i}, \mu_{z}^{i}\right)$ ve $\left(\Phi^{s}, \theta^{s}\right)$ açılarına bağlı olarak (12) denkleminde verildiği gibi hesaplanır (Ding vd., 2009; Cox, 2012; Yuan vd., 2020).

$$
\begin{aligned}
& \mu_{x}^{i+1}=\frac{\sin \theta^{s}}{\sqrt{1-\left(\mu_{z}^{i}\right)^{2}}}\left(\mu_{x}^{i} \mu_{z}^{i} \cos \Phi^{s}-\mu_{y}^{i} \sin \Phi^{s}\right)+\mu_{x}^{i} \cos \theta^{s} \\
& \mu_{y}^{i+1}=\frac{\sin \theta^{s}}{\sqrt{1-\left(\mu_{z}^{i}\right)^{2}}}\left(\mu_{y}^{i} \mu_{z}^{i} \cos \Phi^{s}-\mu_{x}^{i} \sin \Phi^{s}\right)+\mu_{y}^{i} \cos \theta^{s} \\
& \mu_{z}^{i+1}=-\sin \theta^{s} \cos \Phi^{s} \sqrt{1-\left(\mu_{z}^{i}\right)^{2}}+\mu_{z}^{i} \cos \theta^{s}
\end{aligned}
$$

Foton hareket yönü z eksenine çok yakın $\left(\left|\mu_{z}^{i}\right|>0.99999\right)$ ise, hareket yönünün hesabı (13) denkleminde verildiği gibi yapılmaktadır (Cox, 2012).

$$
\begin{aligned}
& \mu_{x}^{i+1}=\cos \left(\Phi^{s}\right) \sin \left(\theta^{s}\right) \\
& \mu_{y}^{i+1}=\sin \left(\Phi^{s}\right) \sin \left(\theta^{s}\right) \\
& \mu_{z}^{i+1}=\frac{\mu_{z}^{i}}{\left|\mu_{z}^{i}\right|} \cos \left(\theta^{s}\right)
\end{aligned}
$$




\subsection{Alinan fotonlar}

Verici birim 1şık kaynağından çıkan fotonların alıcı birim foto-detektör tarafından alınabilmesi için iki şartın aynı anda sağlanması gerekmektedir (Cox, 2012; Tang vd., 2014). Birincisi, ilgili fotonun alıc1 düzlemi üzerindeki herhangi bir noktaya ulaşmasıdır. İkinci şart ise fotonun alıcı düzlemine geliş açısının, foto-detektörün FOV açısı içerisinde olmasıdır. Foto-detektörde lens kullanılıyorsa ki bu çalışmada lens kullanılmıştır, alıcı düzlemi olarak lensin düzleminin dikkate alınması gerekmektedir (Cox, 2012). Dolayısıyla, lens kullanımı alıcı düzlem alanını arttırdığı için fotonların alıcıya ulaşma olasılığını arttırmaktadır (Chen vd., 2020).

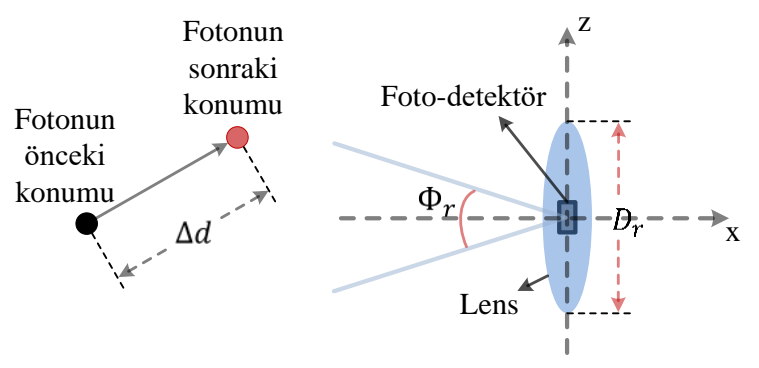

(a)

Fotonun alıcı düzlemine ulaşıp ulaşmadığının algılanabilmesi için, ilgili foton sualtı ortamında her $\Delta d$ mesafesi kadar yol aldiktan sonra foton konumunun foto-detektörün önünde ya da arkasında olup olmadığı kontrol edilir. Alıcı birim ile herhangi bir foton arasında oluşabilecek olası durumlar Şekil 4'te verilmiştir. Pratikte fotodetektör ile kullanılan lens arasında uygun odak uzaklığ 1 kadar bir mesafe bulunmaktadır. Fakat Monte Carlo yaklaşımında takibi yapılan foton, lens düzlemindeki herhangi bir konuma uygun açıda ulaştığında foto-detektör tarafindan alındı kabulü yapıldığından dolayı alıcı birimi tek bir bütün halinde ifade edebilmek için Şekil 4'te lens ve foto-detektör üst üsteymiş gibi gösterilmiştir.

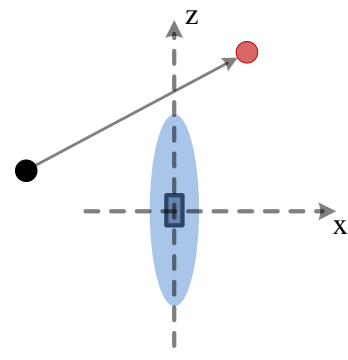

(b)

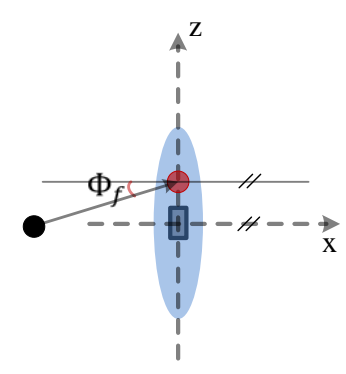

(c)

Şekil 4. Bir foton ile alıcı birim arasında oluşabilecek olası durumların geometrik gösterimi

Fotonun $\Delta d$ mesafesi kadar yol aldıktan sonra alıcı birimin önünde olduğu durum Şekil 4.a'da gösterilmektedir. Bu durumda, foton foto-detektör tarafindan alınmamıştır ve Monte Carlo yaklaşımının blok diyagramındaki işlemler "Emilim Süreci" bloğuyla devam etmektedir. Yol aldıktan sonra fotonun alıcı düzlemini kesmeden foto-detektörün arkasındaki bir konuma geldiği durum Şekil 4.b'de gösterilmiştir. Bu durum için de, Şekil 4.a'daki durum ile aynı işlemler sürdürülmektedir. Şekil 4.c ise, fotonun alıcı lens düzlemine ulaştı̆g durumu göstermektedir. Böyle bir durum söz konusu olduğunda, fotonun alıc1 düzlemini kestiği konum hesaplanmaktadır ve fotonun kesişim noktasına geliş açısının $\left(\Phi_{f}\right)$ fotodetektörün görüş alanında olup olmadığı kontrol edilmektedir. Eğer $\Phi_{f} \leq\left(\Phi_{r} / 2\right) \quad$ şartı sağlanıyorsa, foton alındı kabul edilerek fotonun o anki ağırlığı ve varış zamanı kayıt edilir (Cox, 2012; Tang vd., 2014). Varış zamanı bilgisi, fotonun 1ş1k kaynağından foto-detektöre ulaşana kadar kat ettiği toplam mesafenin, fotonun su ortamındaki hızına oranıla hesaplanmaktadır (Yuan vd., 2020).

\section{Nümerik sonuçlar}

$\mathrm{Bu}$ bölümde, detayları verilmiş olan Monte Carlo yaklaşımı kullanılarak bir UWOC sisteminin kanal dürtü yanıtları, farklı su türleri ve alıcı - verici arası mesafeleri $\left(D_{T x-R x}\right)$ için elde edilmiştir. Elde edilen sonuçlar birbirleriyle karşılaştırılarak yorumlanmıştır. Ele alınan UWOC sisteminin parametreleri Tablo 2'de verilmiş olup, alıcı ve verici birimlerin birbirlerine bakacak şekilde konumlandırıldığı ve haberleşmenin yapıldığı sualtı ortamının homojen bir yapıya sahip olduğu varsayilmıştır.

Sualtı ortamında herhangi bir foton 1 ş1k kaynă̆ından çıktıktan sonra foto-detektöre ulaşabilmesi için geçen en erken süre $\left(t_{0}\right)$ olmak üzere, verici - alıcı arasındaki dik uzaklık $\left(D_{T x-R x}\right)$ ve 1şığın sudaki yayılma hızına bağlı olarak $\quad\left(t_{0}=D_{T x-R x} / v\right) \quad$ denklemiyle hesaplanabilir. Şekil 5, Şekil 6 ve Şekil 7'de sırasıyla berrak, kıyı ve liman su türleri için elde edilen UWOC sisteminin birim vuruş tepkileri verilmiş olup, daha düzgün bir gösterim için kanal dürtü yanıtı eğrileri zaman ekseninde hesaplanan $t_{0}$ süresi kadar kaydırılmıştır $\left(t-t_{0}\right)$. Belirlenmiş her $10^{-10}$ sn zaman aralığında foto-detektörde alınmış olan fotonların ağırlık değerlerinin toplamı, gönderilen bütün fotonların ağırlıklarının toplamına bölünerek normalize edilmiştir ve böylece gönderilen fotonların zamanın hangi anında hangi yoğunlukta alıcıya ulaştıkları hesaplanmıştır (Tang vd., 2014; Dong vd., 2017). 
Tablo 2. UWOC sisteminin parametreleri

\begin{tabular}{|c|c|c|}
\hline \multicolumn{2}{|l|}{ Parametreler } & Değerler \\
\hline \multirow{3}{*}{$\begin{array}{l}\text { Su türü için }(\boldsymbol{a}(\boldsymbol{\lambda}), \boldsymbol{b}(\boldsymbol{\lambda}), \boldsymbol{c}(\boldsymbol{\lambda})) \text { katsayıları } \\
\text { (Petzold, 1972) }\end{array}$} & Berrak & $(0.114,0.037,0.151)$ \\
\hline & Kıy1 & $(0.179,0.219,0.398)$ \\
\hline & Liman & $(0.366,1.824,2.190)$ \\
\hline \multirow{3}{*}{$\begin{array}{l}\text { Saçılma zenit açısının belirlenmesi için } \\
\text { kullanılan Petzold (1972) çalışmasındaki } \\
\text { deneyler }\end{array}$} & Berrak & AUTEC - Test 161 - 13JUL71 - Station 8 \\
\hline & Kiy1 & HAOCE - 05AUG71 - Station 11 \\
\hline & Liman & NUC - 05OCT71 - Station 2040 \\
\hline \multicolumn{2}{|l|}{ Foton say1s1 } & $10^{9}$ \\
\hline \multicolumn{2}{|l|}{ Foton ağırlık eşik değeri } & $10^{-6}$ \\
\hline \multicolumn{2}{|l|}{ Işı̆ğın sudaki hızı $(v)$} & $2.25 * 10^{8} \mathrm{~m} / \mathrm{s}$ \\
\hline \multicolumn{2}{|l|}{ Suyun kırılma indisi $\left(\boldsymbol{n}_{\boldsymbol{s u}}\right)$} & 1.33 \\
\hline \multicolumn{2}{|c|}{ Işı1k dalga boyu $(\lambda)$} & $530 \mathrm{~nm}$ \\
\hline \multicolumn{2}{|c|}{ Alıcı - Verici birimler arasındaki öklid mesafesi $\left(\boldsymbol{D}_{\boldsymbol{T} \boldsymbol{x}-\boldsymbol{R} x}\right)$} & $10 \mathrm{~m}, 15 \mathrm{~m}, 20 \mathrm{~m}, 40 \mathrm{~m}$ \\
\hline \multicolumn{2}{|c|}{ Işı1k kaynağı 1şın yayma açısı $\left(\Phi_{t}\right)$} & $10^{\circ}$ \\
\hline \multicolumn{2}{|c|}{ Işı1k kaynağı normalinin x ekseni ile yaptığı açı $\left(\boldsymbol{\theta}_{\boldsymbol{t}}\right)$} & $0^{\circ}$ \\
\hline \multicolumn{2}{|c|}{ Foto-detektör görüş alanı $\left(\Phi_{r}\right)$} & $180^{\circ}$ \\
\hline \multicolumn{2}{|c|}{ Foto-detektör normalinin x ekseni ile yaptığ açı $\left(\boldsymbol{\theta}_{\boldsymbol{r}}\right)$} & $180^{\circ}$ \\
\hline \multicolumn{2}{|c|}{ Lens çap $1\left(\boldsymbol{D}_{\boldsymbol{r}}\right)$} & $50 \mathrm{~cm}$ \\
\hline \multicolumn{2}{|c|}{ Birim vuruş tepkisinin hesabı için kullanılan zaman aralığı } & $10^{-10} \mathrm{sn}$ \\
\hline
\end{tabular}
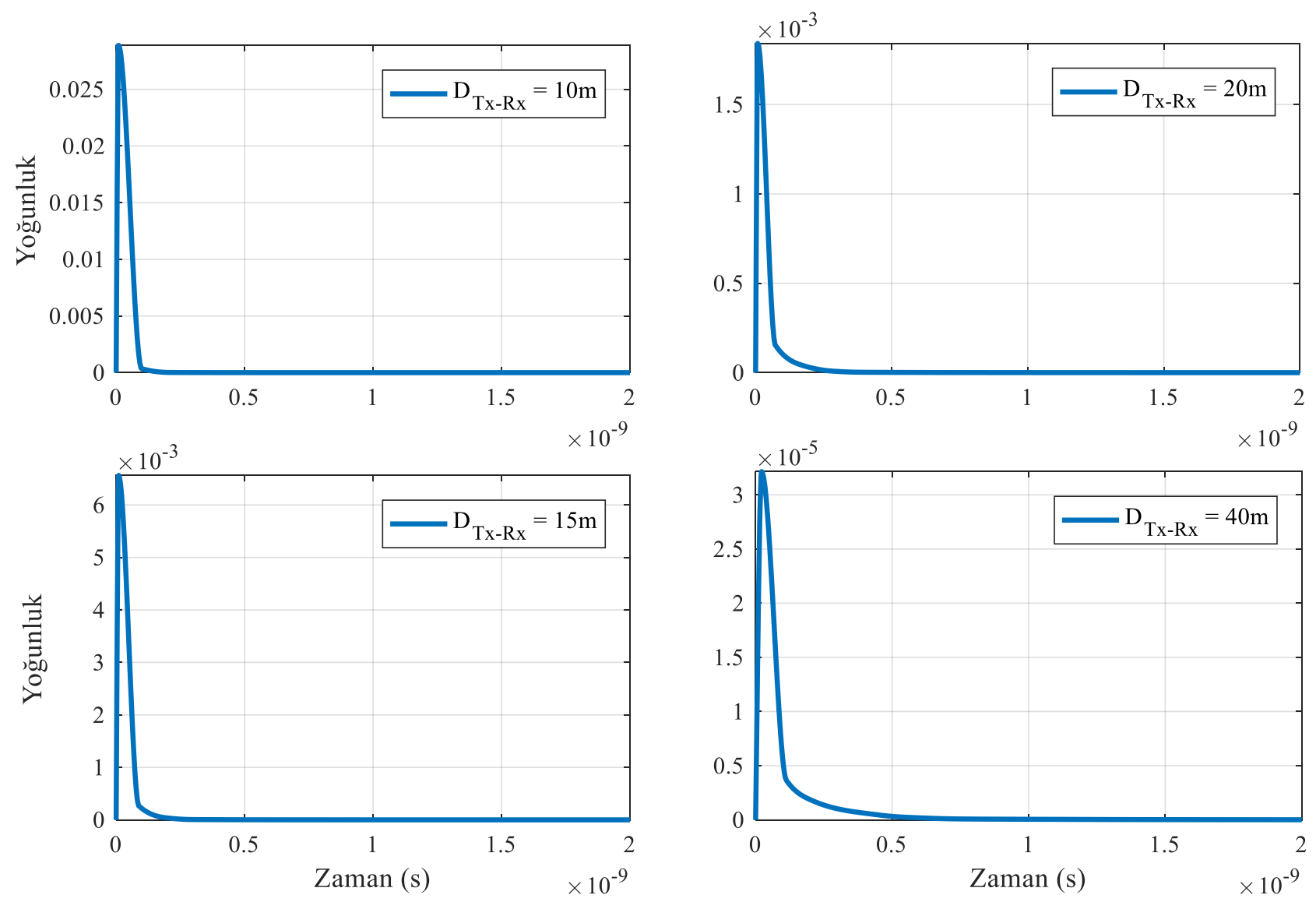

Şekil 5. Berrak su türünde farklı verici - alıcı arası mesafeleri için elde edilen kanal dürtü yanıtları 

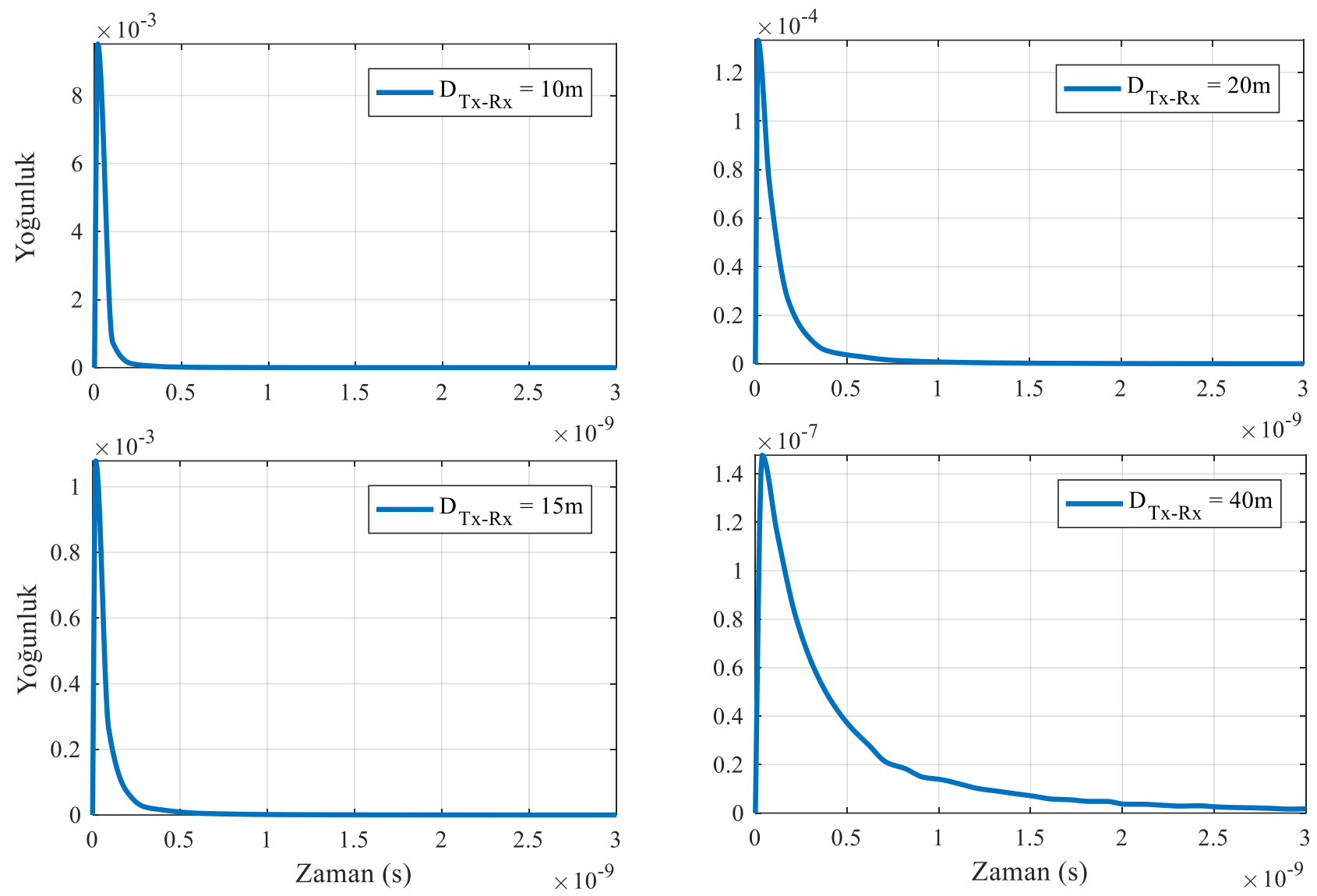

Şekil 6. Kıyı su türünde farklı verici - alıcı arası mesafeleri için elde edilen kanal dürtü yanıtları
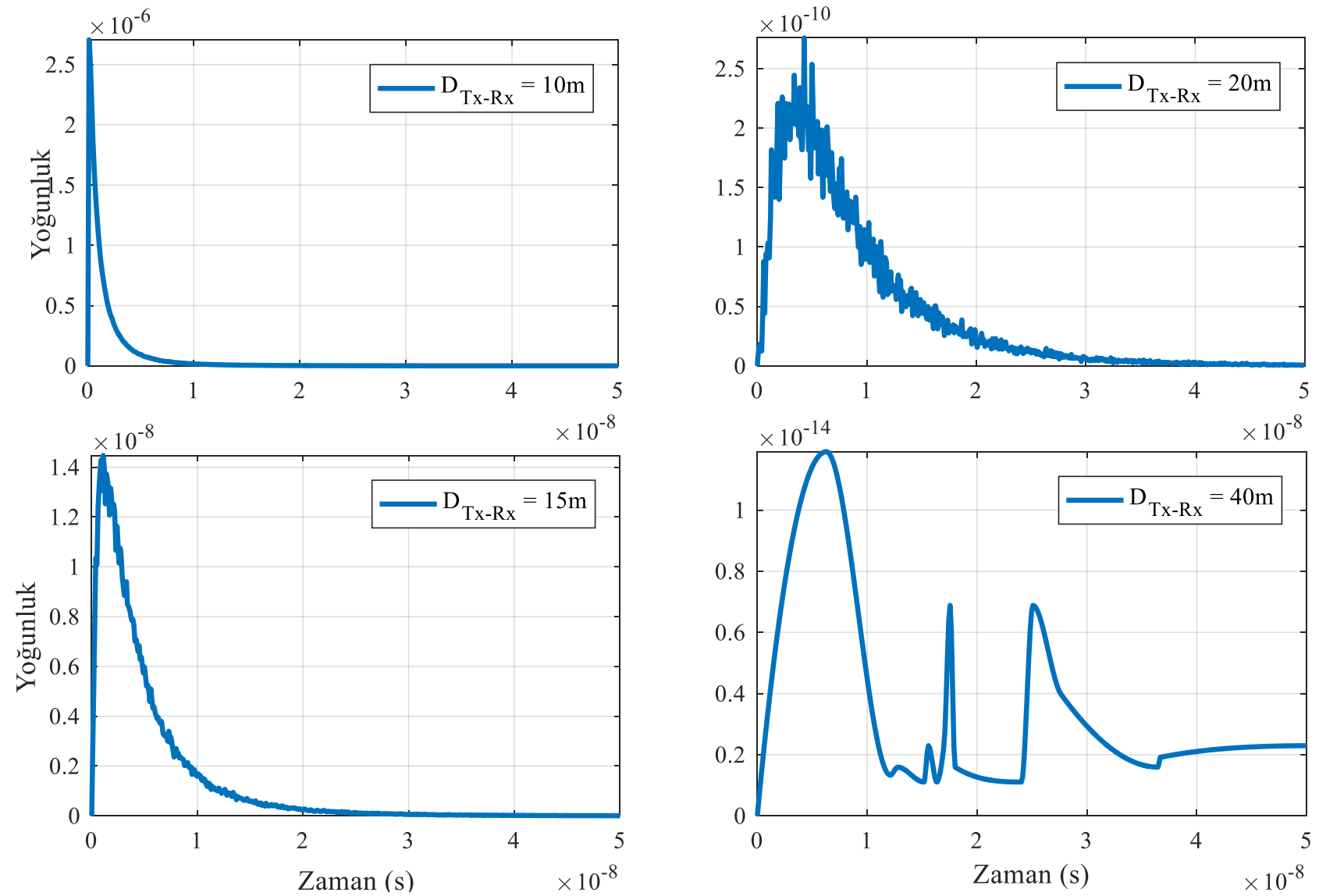

Şekil 7. Liman su türünde farklı verici - alıcı arası mesafeleri için elde edilen kanal dürtü yanıtları 
Elde edilen sonuçların literatür ile uyumlu olduğu gözlenmiş olup (Tang vd., 2014), alıcı ve verici arasında herhangi bir nesneden yansima olmamasına rağmen sualtı ortamının saçılma etkisinden dolayı dürtü tepkilerinin zamanda yayıldığ 1 görülmektedir. $D_{T x-R x}$ mesafesi arttığında fotonların sualtı ortamında maruz kalacağı saçılma miktarı artacağından, Şekil 5, Şekil 6 ve Şekil 7'de görüldügü gibi, dürtü tepkilerinin zamanda yayılma süreleri artmaktadır. Benzer şekilde, $D_{T x-R x}$ mesafesi arttığında, $1 s ̧ 1 \mathrm{k}$ kaynağından çıkan fotonların alıcıya ulaşana kadar maruz kalacakları emilim miktarı da artacaktır. Dolayısıyla, mesafe arttıkça foto-detektörde alınan fotonların ve buna bağlı olarak dürtü tepkilerinin yoğunlukları (intensity) daha da azalmaktadır.

Ele alınan su türlerinin Tablo 2'de verilen emilim ve saçılma katsayıları büyükten küçüğe doğru liman, kıyı ve berrak su şeklinde sıralanmaktadır. Dolayısıyla, dürtü yanıtlarındaki en fazla zaman yayılmasının ve yoğunluk azalışının liman su türünde, sonrasında ise sirayla kıyı ve berrak su türlerinde olması beklenmektedir. Şekil 5, Şekil 6 ve Şekil 7'de verilen dürtü yanıtları da beklenen bu sonucu göstermektedir. Zamanda en fazla yayılma ve yoğunluk azalışı Şekil 7'de liman suyu için verilen sonuçlarda gözlemlenirken, en az yayılma ve yoğunluk azalışı ise Şekil 5'te berrak su türünde gerçekleşmektedir.

$\mathrm{Su}$ ortamının emilim ve saçılma bozucu etkileri, doğrudan UWOC sisteminin haberleşme mesafesini etkilemektedir. Şekil 8'de, ele alınan UWOC sisteminde verici olarak 1 watt güce sahip bir 1şık kaynağının kullanıldığı durum için, farklı su ortamlarında alınan optik güçlerin mesafeye bağlı olarak değişimleri verilmiştir. Berrak suda, ele alınan diğer su türlerine göre, bozucu etkilerin baskınlığı daha az olduğundan dolayı bilgi iletişiminin daha uzun, liman suyunda ise diğer su türlerine göre bilgi iletişiminin daha kısa mesafelerde yapılabileceği görülmektedir.

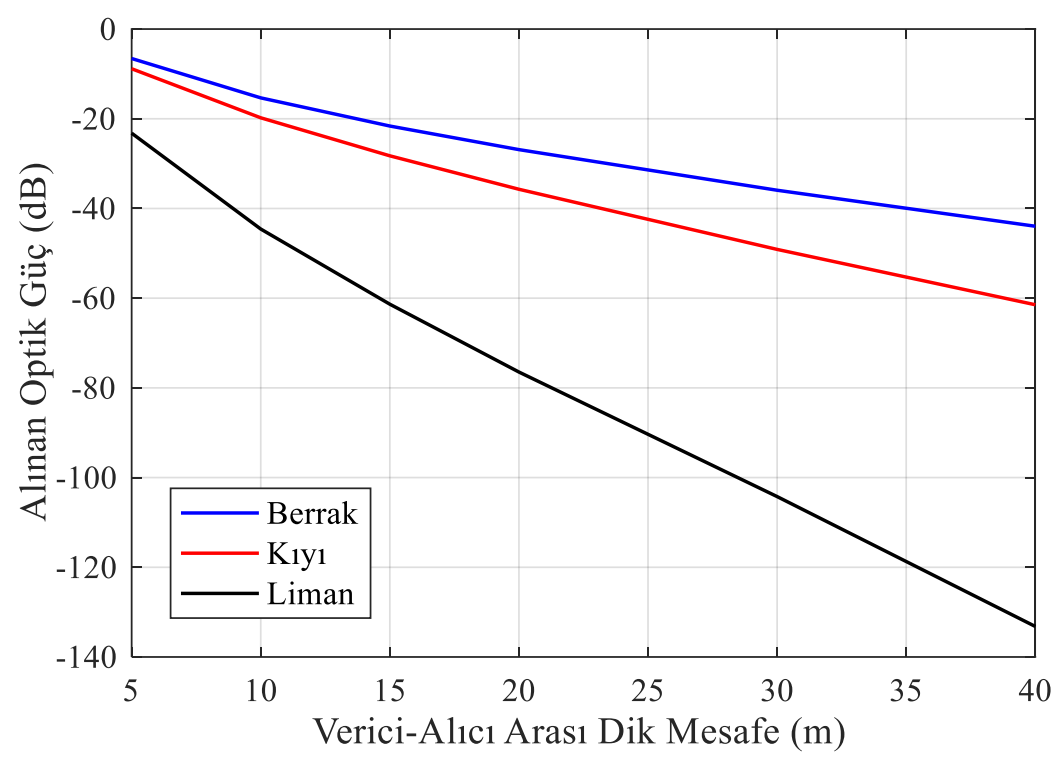

Şekil 8. Alınan optik gücün verici - alıcı mesafesine göre değişimi

Monte Carlo yaklaşımıyla elde edilen kanal dürtü yanıtlarından faydalanılarak ele alınan UWOC sistemi için kanal DC kazancı $\left(H_{0}\right)$, ortalama karekök gecikme yayılımı $\left(\tau_{R M S}\right)$ gibi yararlı kanal parametreleri hesaplanabilir. Kanalın DC kazanc1 ve ortalama karekök gecikme yayılımı parametrelerinin hesab1 surasiyla (14) ve (15) denklemleriyle yapılmaktadır (Miramirkhani ve Uysal, 2017). Bu denklemlerde $h(t)$ Şekil 5, Şekil 6 ve Şekil 7'de de verilmiş olan kanalın dürtü yanitını temsil etmektedir. $\tau_{0}$ ise kanalın ortalama gecikme yayılımını ifade etmektedir ve (16) denkleminde verildiği gibi hesaplanmaktadır.

$$
\begin{aligned}
& H_{0}=\int_{0}^{\infty} h(t) d t \\
& \tau_{R M S} \\
& =\sqrt{\int_{0}^{\infty}\left(t-\tau_{0}\right)^{2} h(t) d t / \int_{0}^{\infty} h(t) d t} \\
& \tau_{0}=\int_{0}^{\infty} t h(t) d t / \int_{0}^{\infty} h(t) d t
\end{aligned}
$$


Tablo 3. Berrak, kıyı ve liman su türlerinde, verici - alıcı arasındaki farklı mesafe değerleri için kanal parametreleri

\begin{tabular}{|c|c|c|c|}
\hline $\begin{array}{c}\text { Su } \\
\text { Türü }\end{array}$ & $\begin{array}{c}\boldsymbol{D}_{\boldsymbol{T x}-\boldsymbol{R} x} \\
(\mathbf{m})\end{array}$ & $\begin{array}{c}\boldsymbol{\tau}_{\boldsymbol{R M S}} \\
(\mathbf{n s})\end{array}$ & $\boldsymbol{H}_{\mathbf{0}}$ \\
\hline \multirow{3}{*}{ Berrak } & 10 & 0.04139 & $2.9263 * 10^{-2}$ \\
\cline { 2 - 4 } & 20 & 0.1197 & $2.0525 * 10^{-3}$ \\
\cline { 2 - 4 } & 40 & 0.3555 & $4.0108^{*} 10^{-5}$ \\
\hline \multirow{4}{*}{ K1y1 } & 10 & 0.1033 & $1.0516^{*} 10^{-2}$ \\
\cline { 2 - 4 } & 20 & 0.3963 & $2.6812^{*} 10^{-4}$ \\
\cline { 2 - 4 } & 40 & 1.6458 & $7.1274 * 10^{-7}$ \\
\hline \multirow{3}{*}{ Liman } & 10 & 2.9188 & $3.4845^{*} 10^{-5}$ \\
\cline { 2 - 4 } & 20 & 7.6657 & $2.2545^{*} 10^{-8}$ \\
\cline { 2 - 4 } & 40 & 11.4730 & $4.7884 * 10^{-14}$ \\
\hline
\end{tabular}

Ele alınan UWOC sisteminin berrak, kıyı ve liman su türlerindeki $\tau_{R M S}$ ve $H_{0}$ kanal parametreleri verici - alıcı arasındaki farklı mesafe değerleri için Tablo 3'te verildiği gibi hesaplanmıştır. Tablodaki sonuçlardan görüldüğü gibi verici - alıcı arasındaki mesafe arttığında, haberleşme kanalının ortalama karekök gecikme yayılımı artarken, DC kazanc1 azalmaktadır. Tablo 3'te hesaplanan parametrelerin ve Şekil 5, Şekil 6, Şekil 7'deki kanal dürtü yanıtlarının literatürdeki çalışmalarda elde edilen sonuçlarla uyumlu oldukları gözlemlenmiştir (Tang vd., 2014; Miramirkhani ve Uysal, 2017).

\section{Sonuçlar}

$\mathrm{Bu}$ çalışmada, güvenilir UWOC sistemlerinin tasarımında gerekli olan UWOC kanal dürtü yanıtının elde edilebilmesi için kullanılan Monte Carlo yaklaşımı detaylı olarak ele alınmıştır. Literatürde karşılaştırma için yaygın olarak tercih edilen berrak, kıyı ve liman su türleri ele alınarak, bir UWOC sisteminin farklı verici - alıc1 mesafelerindeki dürtü yanıtları elde edilmiştir. Sonuçlar göstermiştir ki, her su türünde mesafe arttıça emilim ve saçılma bozucu etkilerinin baskınlığı hızla artmaktadır. Bunun sonucunda da UWOC kanalının dürtü yanıtının zamanda yayılma süresi alıc1 ve verici arasında herhangi bir nesneden yansıma olmamasına rağmen sualtı ortamının yüksek saçılma etkisinden dolayı artmakta iken, yoğunluğu ise azalmaktadır. Elde edilen sonuçlar kullanılarak ihtiyaç duyulan ortam, verici-alıcı arası mesafe ve haberleşme hızındaki UWOC senaryosu için sistem sınırları belirlenebilir ve verici-alıcı yapıları tasarlanabilir. Amaçlanan senaryoya göre direk görüş durumunda bile çok yollu kanal etkilerinin ortaya çıkacağ anlaşılmaktadır. Bu çalışmada elde edilen sonuçlar ile sualtında optik haberleşme vasitasıyla kablosuz olarak yüksek hızlı veri iletişiminin sağlanabileceği gösterilmiştir. UWOC sistemlerinin sağladığı yüksek hızlı veri iletişim sistemleri ile sualtındaki bir insansız sualtı aracından eş zamanlı görüntü aktarımının kablosuz olarak yapılabilmesi mümkün hale gelmektedir. Dolayısıyla UWOC sistemleri, arkeolojik araştırmalar, sualtı keşif ve gözetleme, denizaltı kurtarma gibi birçok sualtı endüstriyel uygulama alanında kablosuz bilgi aktarımının yapılabilmesine olanak sağlamaktadır.

\section{Kaynaklar}

Cox, W.C. (2012). Simulation, modeling, and design of underwater optical communication systems. Doktora Tezi, Department of Electrical Engineering, North Carolina State University, Raleigh, NC, USA.

Chen, H., Chen, X., Lu, J., Liu, X., Shi, J., Zheng, L., Liu, R., Zhou, X. and Tian, P. (2020). Toward long-distance underwater wireless optical communication based on a high-sensitivity single photon avalanche diode. IEEE Photonics Journal, 12(3), 7902510.

Ding, H., Chen, G., Majumdar A.K., Sadler, B.M. and $\mathrm{Xu}, \mathrm{Z}$. (2009). Modeling of non-line-of-sight ultraviolet scattering channels for communication. IEEE Journal on Selected Areas in Communications, 27(9), 1535-1544.

Dong, F., Xu, L., Jiang, D. and Zhang, T. (2017). MonteCarlo-based impulse response modeling for underwater wireless optical communication. Progress in Electromagnetics Research M, 54, 137-144.

Gabriel, C., Khalighi, M.A., Bourennane, S., Leon, P. and Rigaud, V. (2013). Monte-Carlo-based channel characterization for underwater optical communication systems. IEEE/OSA Journal of Optical Communications and Networking, 5(1), $1-12$.

Kaushal, H. and Kaddoum, G. (2016). Underwater optical wireless communication. IEEE Access, 4, 1518-1547.

Miramirkhani, F. and Uysal, M. (2017). Visible light communication channel modeling for underwater environments with blocking and shadowing. IEEE Access, 6, 1082-1090.

Petzold, T.J. (1972). Volume scattering functions for selected ocean waters. Scripps Inst. Oceanogr., La Jolla, CA, USA, Tech. Rep. SIO 72-78.

Prahl, S.A., Keijzer, M., Jacques, S.L. and Welch, A.J. (1989). A Monte Carlo Model of light 
propagation in Tissue. Proc. of SPIE Dosimetry of Laser Radiation in Medicine and Biology, IS 5, 102-111.

Shihada, B., Amin, O., Bainbridge, C., Jardak, S., Alkhazragi, O., Ng, T.K., Ooi, B., Berumen, M. and Alouini, M.-S. (2020). Aqua-Fi: delivering internet underwater using wireless optical networks. IEEE Communications Magazine, 58(5), 84-89.

Tang, S., Dong, Y. and Zhang, X. (2014). Impulse response modeling for underwater wireless optical communication links. IEEE Transactions on Communications, 62(1), 226-234.

Yuan, R., Ma, J., Su, P., Dong, Y. and Cheng, J. (2020). Monte-Carlo integration models for multiple scattering based optical wireless communication. IEEE Transactions on Communications, 68(1), 334-348.

Zeng, Z., Fu, S., Zhang, H., Dong, Y. and Cheng, J. (2017). A Survey of underwater optical wireless communications. IEEE Communications Surveys \& Tutorials, 19(1), 204-238. 